\title{
A Decade of Reviews on Leadership: A Conceptual Perspective and Direction
}

\author{
Lesley Page \\ Lewis University \\ Michele Riley Kramer \\ Lewis University \\ George Klemic \\ Lewis University
}

\begin{abstract}
Organizations, as complex adaptive systems, evolve and what constitutes effective leadership in organizations has evolved as well. We studied integrative reviews and meta-analyses related to leadership from the years 2008-2018. Our findings identified four themes of leadership study: leadership style, training and development, leadership competencies, and employee engagement. Expansion of transformational leadership, with its emphasis toward ethical, empowering, and participative approaches to leadership, are driving a need for leaders to improve their soft skills, re-examine the importance of employee engagement, and shift their focus to employee enrichment.
\end{abstract}

Keywords: Integrative Review, Transformational Leadership, Employee Engagement, Training and Development

\section{INTRODUCTION}

The abundance of literature regarding leadership is mindboggling. A Summon database search using the subject term leadership yielded:

- $\quad 11,862$ journal articles from 1990-2000

- 37,320 journal articles from 2001-2010

- $\quad 54,770$ journal articles from 2011-2018

A search using leadership books on Amazon yielded over 60,000 books. With so much written, how does an individual navigate this sea of knowledge to understand what is pertinent to know about leadership?

Discussing an interdisciplinary curriculum about leadership (nursing, organizational leadership, business), the authors began the dialog about the nature of current leadership studies. The authors determined that looking at the integrative reviews and meta-analyses on leadership over the last 10 years might provide an overview on the current context of leadership knowledge.

Leadership is critical to an organization's success. Organizations have evolved in response to societal and economic change (Laloux, 2014). In order to stay relevant and effective, leadership must respond and 
change to fit the dynamics occurring in organizations. Therefore, views of leadership from a decade ago should not be the same as today.

The purpose of this article is to examine the peer-reviewed journal literature about leadership since 2008, focusing exclusively on integrative reviews and meta-analyses, to look for commonalities, patterns, and emerging topics. Specifically:

- How does the literature focus on leadership?

- What topics are researched most frequently?

- How have expectations of leadership changed?

The conceptual framework used in this review is complexity science. Organizations, people, and society can be seen as complex adaptive systems (CASs). Such systems are interconnected with their elements in a way that is nonlinear and unpredictable (Lindbergh, Nash, \& Lindberg, 2008; Patton, 2011; Suchman, 2002). There is no central control, and behaviors are co-evolving and co-emerging. Small change can produce unexpected and unanticipated outcomes (Lindbergh et al., 2008; Patton, 2011; Suchman, 2002). These CASs are adaptive, diverse, and teetering at the edge of order-disorder (Lindbergh et al., 2008; Patton, 2011; Suchman, 2002). If the overall purpose of leaders is to influence, then leaders operating within CASs need criteria and tools that are different from previous times.

\section{Method}

The authors followed Torraco's (2005) framework for integrative literature reviews. Criteria for selecting journal articles included:

- Available in the Summon database;

- Integrative review, systematic review, or meta-analyses methodology;

- Addressing the topic of leadership;

- Published between January, 2008 and December, 2018.

A Summon database search for journal articles included the search terms leadership, integrative review, integrative literature review, and systematic review, which initially yielded 370 articles. A review of the abstract reduced the number to 143 articles meeting the search criteria.

\section{Phase I}

The first 30 articles in the results list were reviewed and sorted into a table. The authors brainstormed and identified 14 concepts addressed in the articles (See Table 1). Inter-rater consensus of the concepts addressed in the articles was determined by each author reading the same three articles and identifying the concepts. Discussion resulted in agreement regarding categorization and calibration of topic selection. 
TABLE 1

CONCEPTS IN THE LITERATURE

\begin{tabular}{|l|}
\hline \multicolumn{1}{|c|}{ Phase I Categories Identified } \\
\hline 1. Leadership Training, Education and Development \\
2. Abusive / Dysfunctional Leadership / Psychological Safety \\
3. Ethical Leadership, Climate, Trust \\
4. Authentic Leadership (virtuousness) \\
5. Emotional Intelligence/Emotional Regulation \\
6. Change Management/Organizational Change \\
7. Leadership Types/Styles \\
8. Global Leadership/Globalization Differences \\
9. Diversity (Individual Differences/GLBT) \\
10. Leadership Competency \\
11. Groups/Teams \\
12. Employee Engagement \\
13. Leadership Models \\
14. Board Leadership
\end{tabular}

Phase II

The authors subsequently reviewed the rest of the articles. The concepts and interrater consensus discussion determined in Phase I were used to categorize the remaining articles and identify additional concepts. Each author completed a table of the article reviews with the following column titles:

- Reference

- Phase I Concept(s) Identified

- Other Concepts \& Findings

- Comments

Discussion of the articles helped illuminate topics addressed, commonalities, and differences. The 14 concepts were tallied by the number of articles addressing them. Frequency ranged from 1-27. The top four concepts with the highest counts (frequency 19-27) were identified. They formed the basis of a short summary article by the authors discussing emerging future ideas related to leadership (Kramer, Page, \& Klemic, 2018).

\section{Phase III}

An additional literature search in Summon was conducted to identify any new integrative reviews or meta-analyses published between January and December, 2018. The search found eight additional articles for review and analysis.

Findings were grouped under the four highest-frequency concepts identified in Phase II. All 14 categories from Phase I can easily be subsumed into one of the four. This integrative review focused on the concepts and topics from the reviews that related to leadership. Discussion is framed according to the four concepts: 1) Leadership Styles, with a more in-depth discussion about transformational leadership; 2) Leadership Training and Development; 3) Leadership Competency; and 4) Leadership and Employee Engagement.

\section{LEADERSHIP STYLES}

A few styles of leadership considered effective were found, with further discussion on emerging styles that seemed to evolve from the literature on transformational leadership, which appears to be considered the gold standard for leadership aspiration. Other styles mentioned besides transformational 
leadership in a systematic review of leadership process models, encompassing 205 articles, were leadermember exchange (LMX), empowering leadership, and ethical leadership (Fischer, Dietz, \& Antonakis, 2017). Hoch, Bommer, Dulebohn and Wu (2018) addressed three styles of leadership considered to be forms of positive leadership that focus on ethical and moral aspects of leading. They believe authentic and ethical leadership styles are not especially different from transformational leadership. However, servant leadership stood out as a distinct form that could be studied on its own. The authors recommended adding a stronger moral dimension to the transformational leadership model to make it more complete. Chiaburu, Smith, Wang, and Zimmerman (2014) studied the relationship between three styles of leadership within the context of influence: contingent reward (transactional); leader-member exchange (LMX-relations); and transformational (change-oriented). All were positively associated with employee proactive behavior and task performance.

People-focused, collaborative leadership styles were the most researched, as these approaches reflect the changing nature of the workplace today (e.g., more teams and collaboration). Interestingly, while these factors relate directly to transformational leadership, they can be connected to other leadership styles as well. Participative and empowering leadership were found to be important in building trust and respect among leaders and followers. By engaging others through participative methods (i.e., soliciting feedback, sharing ideas, etc.), followers tend to respond positively to their leader. This can have positive outcomes on performance and satisfaction (Bezerra de Lima, Gomes do Norte, de Araujo, Teixeira, \& Lopes, 2016). Participative leadership is also at the basis of more modern organizational structures, which focus on teamwork and matrixed relationships, i.e., less hierarchical (Bezerra de Lima et al., 2016). Kim, Beer, and Prewett (2018) looked at the relationship between empowering leadership behaviors and follower evaluations of leaders. Empowering leadership resulted in more favorable evaluations of the leader, as well as better employee motivation, work attitudes, and performance (Kim et al., 2018). These findings suggest the people-focused qualities associated with leadership are impactful in today's organizations.

Several studies addressed leadership in teams (Annix, Wilkes, \& Daly, 2013; D'Innocenzo, Mathieu, \& Kukenberger, 2014; Morgeson, DeRue, \& Karam, 2010; Nielsen, Randall \& Christensen, 2010; Pratoom, 2018; Wang, Waldman \& Zhang, 2014). This may point to the future directions of leadership knowledge, which coincides with the next iteration of organizational structure (Laloux, 2014). Annix et al. (2013) found that leaders with a follower/team focus possessed attributes necessary to sustain a supportive workplace. In their study, a team focus helped leaders build capacity and resilience in a healthcare setting, although it is likely such results could be generalized to other populations as well. Pratoom (2018) found that people-focused and task-focused leadership were moderated by several team variables such as team size, team characteristics and culture. People-focused leaders were most impactful in cultures with low power distance when team size was small and interdependence was low. Power distance is the extent to which the less powerful expect and accept that power is distributed unequally (Hofstede \& Hofstede, 2005). In these situations, people-focused leaders could create more effective teams (Pratoom, 2018).

Recent trends in research indicate that the leader-follower relationship and people-focused leadership continue to be the focal point of understanding team effectiveness, result in sustained capabilities and performance, and build employee trust through increased personal attention and involvement.

\section{Dark Side/ Dysfunctional Leadership}

Some reviews addressed the dysfunctional or negative aspects of leadership, perhaps as a sign of the literature's acknowledgement of the dark side of leadership behavior. Dysfunctional leaders create an organizational environment of disrespect, psychologically negative skewing of relationships, and have a negative impact and cost for the organization and employees (Rose, Shuck, Twyford, \& Bergman, 2015). Rose et al. (2015), in their integrative review spanning several disciplines (e.g., psychology, management, healthcare), classified dysfunctional leadership behaviors across a four-quadrant grid, from low to high,

for annoyance and trauma. They identified three themes from their review of 67 articles: 1) the types of behaviors seen in dysfunctional leaders; 2) the short-term and long-term impact in the work environment; 
and 3) effective strategies to counteract the outcomes of these behaviors. Strategies included management training, recognizing and preventing this type of leader from assuming a position, and attention to the organization structure and culture in order to mitigate the effects and severity of any dysfunction.

Gaddis and Foster (2015) noted that nearly two-thirds of leaders globally act destructively, with an estimated organizational cost of \$1.5-2.7 million. They used a survey they created, the Hogan Developmental Survey, which includes 11 dark-side dimensions of personality. They surmise that, globally, job analysis ratings indicate that who the leader is is more important than what the leader does (competency), which supports the emerging emphasis on ethical, authentic, and servant leadership.

Narcissism and its impact on leadership has been evaluated in the context of organizational psychology's focus on negative workplace behaviors (Grijalva, Harms, Newman, Gaddis, \& Fraley, 2015). Extraversion is strongly linked to leadership behavior, and narcissism is related to extraversion. Moderate levels of narcissism were found to contribute to leadership effectiveness but there was a point beyond moderate where it became inversely related to effectiveness (Grijalva et al., 2015).

\section{Transformational Leadership}

This integrative review of leadership research over the last decade reinforced that transformational leadership is here to stay. While many styles and approaches to leadership exist (transactional, positive, value-based, servant, authentic, super leadership, etc.), several integrative reviews and meta-analyses continue to focus on transformational leadership specifically.

Although transformational leadership has been studied for many decades, originating in early work by James MacGregor Burns (Wren, 1995), it has evolved over the years to focus on three key characteristics: inspirational appeal, individual consideration, and intellectual stimulation (Nahavandi, 2015). Inspirational appeal describes the leader's charismatic and motivational presence, especially in building trust and respect with employees. Individual consideration draws on the one-to-one relationships that form between leader and follower. Lastly, intellectual stimulation focuses on the means by which transformational leaders engage others and build upon their knowledge/learning to make better, wellinformed decisions (Nahavandi, 2015). While these key characteristics continue to be the foundation for transformational leadership, the research surrounding this leadership style has evolved over the last decade to reflect the changing needs and complexities of $21^{\text {st }}$ century organizations.

The new age of transformational leadership research focuses on how transformational leaders can build human capital through training and development (competence and knowledge creation), the relationship between transformational leadership and emotional intelligence (especially when it comes to inspirational appeal and intellectual stimulation) and cultural considerations given the multicultural and dynamic nature of today's organizations. Leaders in today's organizations require demonstrated skill with the softer skills that build bonds of trust and respect with their followers (Nienaber, Romeike, Searle \& Schewe, 2015). This becomes particularly relevant as leaders become responsible for training, development, and talent management within their organizations (Lacerenza, Reyes, Marlow \& Salas, 2017). Leaders are responsible for alignment of employee goals with organizational outcomes, building skills to ensure productivity and development of leadership talent. This typically occurs through learning transfer and practice, which can be encouraged through the 'soft skill' talents associated with a transformational approach. Characteristics such as inspiration, motivation, consideration, and relationship building are key.

Additionally, research trends focus on the strong relationship that exists between transformational leaders and emotional intelligence. Emotional intelligence (Goleman, 1995) encompasses many of those same softer skills that combine self-knowledge (self-management and self-monitoring) with knowledge of others (through situational and interpersonal analysis). Our integrative review found that many researchers continue to have interest in the intersection of transformational leadership and emotional intelligence and related organizational outcomes. Emotional intelligence has been found to be most highly correlated with inspirational motivation and intellectual stimulation (Kim \& Kim, 2017). However, other researchers believe the relationship between transformational leadership and emotional intelligence may not be as strong as currently thought, calling for better tools to measure emotional intelligence (Harms \& 
Crede, 2010). Nevertheless, the common themes that emerge across research continue to reinforce the strength of transformational leaders through their ability to use their own power and inspiration effectively, work collaboratively with others to build trust and respect and develop organizational outcomes related to knowledge sharing and creation (Kim \& Kim, 2017).

New styles of leadership seem to evolve from transformational leadership, such as authentic, servant, and super leadership. Along these lines, transformational leadership has been compared to other leadership styles that also embrace the dynamics of the leader-follower bond, specifically authentic, and servant leadership (Hoch et al., 2018). According to Hoch et al. (2018), authentic, servant, and transformational leadership share a common thread in terms of the aspect of morality or ethics in leadership. As an issue that many organizations struggle with today, morality (or lack of) can be a major obstacle to organizational effectiveness. Transformational leaders were most aligned with authentic

leadership, both sharing qualities of an interest in morality and doing what was right for the organization (Hoch et al., 2018). Servant leadership emerged as a related, but unique approach to leadership. These researchers suggest adding a stronger moral component to transformational leadership to make it even more complete.

As organizations change and grow, they have become more culturally diverse. Leaders who demonstrate a cultural mindset can be most effective working with others across cultural, gender and generational divides (Nahavandi, 2015). Rockstuhl, Dulebohn, Ang, and Shore (2012) found that transformational leaders draw upon leader-member exchange models (LMX) to foster an interpersonal connection with those they work with. We see this manifest as individual consideration. The more culturally aware leaders are, the better equipped they will be to develop positive relationships with others. Leong and Fischer (2011) predicted that transformational leadership may be better aligned with cultural dimensions such as cultural mastery and egalitarianism although further research is needed to explore when/why these relationships exist.

An added characteristic that can be expanded into transformational leadership descriptions, or become a new style emerging from it, is the notion of compassionate leadership. It includes the idea of shared, distributive, and adaptive qualities of leadership (de Zulueta, 2016).

Self-efficacy within a leader was studied in one review, which found that leaders with a high degree of self-efficacy have outstanding outcomes in their ability to influence others but, taken to the extreme, can inversely affect employee efficacy (Paglis, 2010).

Whether in healthcare (Moura, Bernardes, Balsanelli, Zanetti \& Gabriel, 2017) or higher education (Balwant, 2016), research trends continue to show the longevity of transformational leadership as a go-to model for effective leadership behavior. Associated with positive organizational outcomes such as workplace satisfaction, organizational commitment, and work engagement, transformational leaders show their perseverance in meeting the challenges, demands and expectations that modern organizations face. While other leadership styles have been studied, transformational leadership continues to be the most prominent.

\section{LEADERSHIP TRAINING AND DEVELOPMENT}

Twenty-first century organizations operate in an increasingly complex environment. Leaders in those organizations must wield tools that are up to the task, and both the tools and the leaders who use them must evolve as the environment does. In other words, leaders must behave as life-long learners and continually develop their skills. We found positive outcomes where transformational leaders are linked to a capacity for further development. (Kramer, et al., 2018). Manderscheid and Ardichvili (2008) identify the importance of a leader's impact on human capital. An organization can only increase its human capital by talent acquisition and/or by training and development. The scope and efficacy of training and development is therefore of vital importance to $21^{\text {st }}$ century leaders. 


\section{Importance of "Soft" Skills Development}

In our analysis of integrative review and meta-analyses literature, we found "soft" skill development was often linked to leadership training and development. Lacerenza et al. (2017), for example, found that soft-skill training and development improved organizational and subordinate outcomes. Other research found that leadership development in the form of peer-mentor training improved outcomes for undergraduate nursing students (Wong, Stake-Docet, Lombardo, Sanzone \& Tsimicalis, 2016), coaching was found to contribute to continual leader development (Carey, Philippon \& Cummings, 2011), reflective learning - reflection on self-perception-was identified as a necessary component of leader development (Cotter \& Cullen, 2012) and training focused on relationships improved outcomes in developing educators (Robinson, Lloyd \& Rowe, 2008). Additionally, teamwork training, including transformational leadership, was found to positively affect team outcomes (Nielsen et al., 2010).

Training pedagogy seems important as well. Gen Xers and Gen Yers were found to absorb leadership development better in an experiential fashion, using role-modeling and sensemaking activities (Ligon, Wallace \& Osburn, 2011). The transfer effect of training is stronger for low-level leadership development (Lacerenza et al., 2017).

In addition to the soft-skills literature, it was interesting to find that Manderscheid and Ardichvili (2008) discussed leader change in organic terms, rather than mechanical ones. These researchers discussed "transition" to be managed, with the leader and not the followers being in need of adapting. Though not discussed elsewhere in the paper, this move away from traditional, hierarchical direction represented a longer-term trend than contained in the last decade.

Also, of interest was Ligon et al.'s (2011) identification of the need to train leaders to handle the role of "buffer" between the creative talent of the organization and the bureaucrats who might stifle the creative process. Ligon et al., along with Mehdiabadi \& Li (2016), also discuss leadership training and development in terms of the talent of the organization, rather than in terms of the employees. Mehdiabadi \& Li (2016) mention the 2014 re-naming/rebranding of the Association for Talent Development (nee' American Society for Training and Development), which may indicate a subtle change in perception of relationships. If leaders are still leaders, are followers subordinates, or are they talent? If followers are talent, how has the relationship to the leader changed?

\section{LEADERSHIP COMPETENCY}

At a time when followers and leaders are increasing their education level, one would expect there to be a need for increased competency in leadership. As discussed in the previous Training and Development section, the emphasis seems to be on soft skills. We noted a strong orientation away from the past and toward the future, with a leader being expected to wield many skills, both as an individual and as a member of a team. Manderscheid and Ardichvili (2008), for example, discuss the need for newly appointed leaders to be competent as a leader, even as they learn their new role and as the new followers learn theirs. It is suggested that the new leaders must manage impressions, align expectations, manage stress and anxiety, and engage in feedback-seeking behaviors, wielding these competencies on an ongoing basis (Manderscheid \& Ardichvili, 2008).

Coaching is a key competency of a leader in today's organizations (Carey et al., 2011). One model splits coaching into four skills: relationship building; problem-defining and goal setting; problem-solving; and transformation processing (Carey et al., 2011). Yet other leadership researchers see followers as a part of a learning organization (LO), and include LO-supporting competencies such as the ability to support and inspire, facilitation skills, and orientation skills (Alagaraja, 2014).

Truong, Paradies, and Priest (2014) and Bereza de Lima et al. (2016) saw leadership in the healthcare setting as requiring a greater development of cultural competency, along with a greater willingness to draw data and examples from cross-cultural studies. Both teams of researchers saw or expected improved outcomes to flow from attentiveness to the cultural component of leadership skills.

In higher education, there was increased focus on leader-follower and follower-follower relationships, as well as on the core business of learning (Robinson, Lloyd \& Rowe, 2008). Some researchers found that 
instructional leadership (Hallinger, 2003), a model in which a school principal or other leader applied direct pressure by focusing on curriculum and instruction, delivered significantly more influence on followers than transformational leadership (Robinson et al., 2008).

The elder-care sector studied by Nielsen et al. (2010) saw efficacy in training leaders as part of teams. There were improvements in motivation and the social climate, and they suggested that training as team leaders might help with team implementation (Nielsen, et al., 2010).

Ligon et al. (2011) focused on leading in "creative" environments. They identified the creative employee as a special breed, one requiring buffering from the usual, organizational bureaucracy. Leaders were seen as mentors, role-models, and sense-makers.

\section{LEADERSHIP AND EMPLOYEE ENGAGEMENT}

Several integrative reviews specifically addressed employee engagement and were geared to a human resource-intended audience. Some believed employee engagement related more to human resource development than leadership (Shuck, 2011). Nevertheless, leadership is complexly connected to engagement. At the heart of the relationship stems the bond between leaders and followers, building trust and personal relationships, and creating a supportive workplace. Haver, Akerjordet and Furunes (2013), in studying emotional regulation (ER) and its connection with leadership, found leadership style as well as personality factored into how employees used their own ER and job outcomes. The authors said their findings emphasized the highly emotional and contagious process between leaders and followers and the potential impact on both organizational and employee health.

Employee engagement is critical to organizational success and sustainability (Kim, Khan, Wood, \& Mahmood, 2016). Corporate social responsibility (CSR) emerged as a key concept connected to employee engagement as well as organization sustainability (Kim et al., 2016). While Kim et al. (2016) did not directly address leadership, their findings indirectly connect to it by using organizational sustainability (outcomes) and employee engagement as variables that leaders impact.

Trust between leaders and employees was the focus of a few studies. For example, one qualitative meta-analysis found transpersonal leadership had a more positive effect in relation to leadership trust, employees' work behavior, organizational impact, and attitude toward the leaders (Nienaber et al., 2015).

While focused specifically on employee's attitudes regarding change in organizations, and geared toward the human resources rather than the leadership audience, one integrative review nonetheless provided insights to leaders when initiating organizational change (Choi, 2011). Effective leadership practices were mentioned as an antecedent to change, trust in leaders as an antecedent to employee openness to change and cynicism, and belief in leadership effectiveness as an antecedent to cynicism (Choi, 2011).

Leadership's influence on organization citizenship behavior (OCB) was not directly addressed from an integrative review of OCB within the human resource development field but still provided direction for leaders regarding OCB development in employees (Rose, 2016). An organization's learning culture, leadership mentoring, engagement, and learning behavior impact the development of employee OCB (Rose, 2016).

Some studies addressed the relationship between leadership types and employee commitment. Jackson, Meyer, and Wang (2013) distinguished between affective commitment (AC), normative commitment (NC), and continuous commitment (CC). Transformational and charismatic leadership styles were positively associated with both $\mathrm{AC}$ and $\mathrm{NC}$, with $\mathrm{NC}$ 's effect more moderate. Contingent reward and active management by exception were positively related to $\mathrm{AC}$, while laissez-faire and passive management by exception were negatively related to AC (Jackson, Meyer \& Wang, 2013). The authors summed it up thus: "Employees with strong AC want to remain, those with strong NC feel they ought to remain, and those with strong CC believe that they have to remain" (p.86). It's interesting to note from this international study that leadership style moderated culture. Another meta-analysis examining leadership in educational settings in Turkey had similar findings (Çoğaltay \& Karadağ, 2016). 
Additionally, the relationship of leadership on employee mental health and job performance was also addressed (Montano, Reeseke, Franke, \& Huffmeier, 2016). The study made a distinction between highquality leadership positively impacting employee mental health and destructive leadership, which negatively affected employee mental health. Destructive leadership violates organizational social norms and displays aggressiveness to followers as well as negative psychopathic behaviors in the personality disorders diagnostic spectrum (Montano, et al., 2016).

A systematic review studied the connection between leadership and overall employee health and wellbeing (Kuoppala, Lamminpää, Liira \& Vainio, 2008). They found weak evidence associating good leadership with increased job satisfaction, moderate evidence associating it with increased well-being and decreased risk for taking sick leave, and weak evidence associating it with job performance (Kuoppala et al., 2008).

In summary, leadership is strongly connected to an employee's life in several dimensions-work performance, culture, health and well-being, motivation, and retention. Leadership was considered a factor in employee engagement in other human resource reviews (Wollard \& Shuck, 2011; Yahaya \& Ebrahim, 2015), regarding psychological safety (Martinez, 2016) and support for whistleblowers (Jackson et al., 2014).

\section{CONCLUSION}

What does this integrative review of integrative reviews and meta-analyses in the last decade say about leadership? Employee engagement will take increasing priority for leadership in light of the emerging models for organizations (Laloux, 2014), newer change models such as appreciative inquiry, positive psychology, and strategies that have bottom-up rather than top-down strategies (Stavros \& Hinrichs, 2009; Whitney \& Trosten-Bloom, 2010), and the firm entrenchment of seeing organizations as complex adaptive systems (Suchman, Sluyter, \& Williamson, 2011).

There is an evolution in thought regarding both organizations and leaders (See Figure 1).

\section{FIGURE 1 \\ EVOLUTION OF ORGANIZATIONAL CONTEXT, CONCEPTUALIZATION AND STRUCTURE}

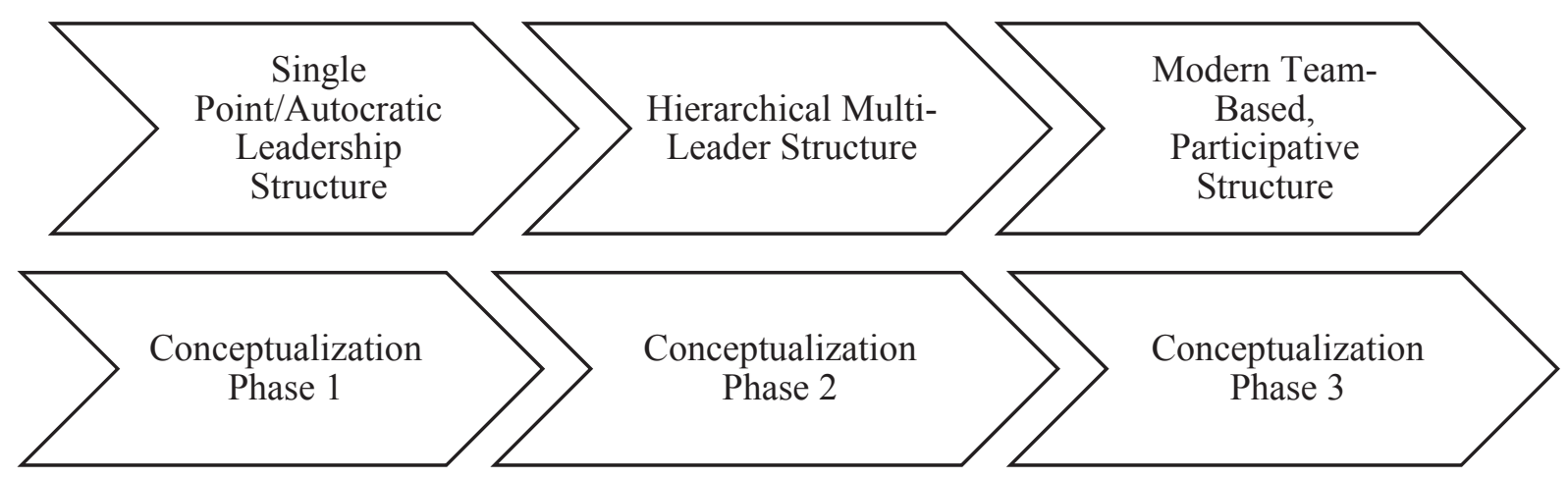

The dynamics of leadership seem to be expanding and evolving similar to the way Gebser (1985) envisioned human consciousness evolution. Gebser saw human consciousness begin with the Archaic (originary) structure of consciousness and subsequently move to Magic (pre-rational), Mythical (irrational), and the current Mental (rational/causal) mindset. He predicted that humanity is moving into the next phase, Integral (arational/acausal), where all previous structures are integrated (Feuerstein, 1987; Gebser, 1985). Leadership is showing signs of becoming integral as well, incorporating more aspects from a number of fields. Laloux's (2014) depiction of organizations follows this evolutionary timeline, 
moving from Reactive (infared) to Magic (magenta) then Impulsive (red), Conformist (amber), Achievement (orange), Pluralistic (green), and now to Evolutionary (teal).

Miles and Scott (2019) define leadership as both a role and a process. It is also an "influencing process" as well as "a dynamic and social process" (pp. 6-7). This duality is not clearly delineated in the literature on leadership. Leadership development should focus on the components of knowing, doing, and being. There is a growing emphasis on developing the soft skills, a greater focus on engaging others, and stimulating internal motivation of individuals. As one of our colleagues once remarked, "there is a fine line between manipulation and motivation," and the direction of leadership development seems to be emphasizing the latter.

Participatory and collaborative approaches should be studied more, with an interest in shared learning of leadership as well. Finally, leading in "creative" context (Ligon, et al, 2011) may spread outside the current entertainment and technological venues to more types of settings as the world wrestles with artificial intelligence, robotics, and the wielding of "big data" in a leadership context.

\section{REFERENCES}

Alagaraja, M. (2014). A conceptual model of organizations as learning-performance systems: Integrative review of lean implementation literature. Human Resource Development Review, 13(2), 207 233. DOI: $10.1177 / 1534484313495852$

Annix, J. M., Wilkes, L., \& Daly, J. (2013). Attributes of clinical leadership in contemporary nursing: An integrative review. Contemporary Nurse, 45(1), 10-21.

Balwant, P. T. (2016). Transformational instructor-leadership in higher education teaching: A metaanalytic review and research agenda. Journal of Leadership Studies, 9(4), 20-42. DOI: $10.1002 / \mathrm{jls} .21423$

Bezerra de Lima, M.A., do Norte, M., Araujo, M.G., Teixeira, G. A., Lopes, T. R. G, Cassiano, A.N....Carvalho, J. B. (2016). Leadership strategies used by health professionals in hospital units: Integrative review. International Archives of Medicine, 9(198), 1-9. DOI: 10.3823/2069

Carey, W., Philippon, D. J., \& Cummings, G. G. (2011). Coaching models for leadership development: An integrative review. Journal of Leadership Studies, 5(1), 51-69. DOI:10.1002/j1s.20204

Chiaburu, D. S., Smith, T. A., Wang, J., \& Zimmerman, R. D. (2014). Relative importance of leader influences for subordinates' proactive behaviors, prosocial behaviors, and task performance: A meta-analysis. Journal of Personnel Psychology, 13(2), 70-86. DOI: 10.1027/18665888/a000105

Choi, M. (2011). Employees' attitudes toward organizational change: A literature review. Human Resource Management, 50(4), 479 - 500. DOI: 10.1002/hrm.20434

Çoğaltay, N., \& Karadağ, E. (2016). The effect of educational leadership on organizational variables: A meta-analysis study in the sample of Turkey. Educational Sciences: Theory \& Practice, 16(2), 603-646. DOI: 10.12738/estp.2016.2.2519

Cotter, R.J., \& Cullen, J.G. (2012). Reflexive management learning: An integrative review and a conceptual typology. Human Resource Development Review, 11(2), 227-253. DOI: $10.1177 / 1534484312438874$

de Zulueta, P.C. (2016). Developing compassionate leadership in health care: An integrative review. Journal of Healthcare Leadership, 2016(8), 1-10. DOI: 10.2147/JHL.S93724

D’Innocenzo, L., Mathieu, J.E., \& Kukenberger, M.R. (2014). A meta-analysis of different forms of shared leadership-team performance relations. Journal of Management, 42(7). 1964-1991. DOI: $10.1177 / 0149206314525205$

Feuerstein, G. (1987). Structures of consciousness: The genius of Jean Gebser--an introduction and critique. Lower Lake, CA: Integral Publishing.

Fischer, T., Dietz, J., \& Antonakis, J. (2017). Leadership process models: A review and synthesis. Journal of Management, 43(6), 1726 -1753. DOI: 10.1177/0149206316682830 
Gaddis, B. H., \& Foster, J. L. (2015). Meta-analysis of dark side personality characteristics and critical work behaviors among leaders across the globe: Findings and implications for leadership development and executive coaching. Applied Psychology: An International Review, 64(1), 2554. DOI: 10.1111/apps.12017

Gebser, J. (1985). The Ever-Present Origin. (N. Barstad \& A. Mickunas, Trans.). Athens, Ohio: Ohio University Press. (Original work published 1966).

Goleman, D. (1995). Emotional intelligence: Why it can matter more than IQ. New York, NY: Bantam Books.

Grijalva, E., Harms, P.D., Newman, D. A., Gaddis, B.H., \& Fraley, R.C. (2015). Narcissism and leadership: A meta-analytic review of linear and nonlinear relationships. Personnel Psychology, 68(1), 1-47. DOI: $10.1111 /$ peps.12072

Harms, P.D., \& Credé, M. (2010). Emotional intelligence and transformational and transactional leadership: A meta-analysis. Journal of Leadership \& Organizational Studies, 17(1), 5- 17. DOI: $10.1177 / 1548051809350894$

Haver, A., Akerjordet, K., \& Furunes, T. (2013). Emotion regulation and its implications for leadership: An integrative review and future research agenda. Journal of Leadership \& Organizational Studies, 20(3), 287-303. DOI: 10.1177/1548051813485438

Hoch, J. E., Bommer, W. H., Dulebohn, J. H., \& Wu, D. (2018). Do ethical, authentic, and servant leadership explain variance above and beyond transformational leadership? A meta-analysis. Journal of Management, 44(2), 501-529. DOI: 10.1177/0149206316665461

Hofstede, G., \& Hofstede, G.J. (2005). Cultures and Organizations: Software of the Mind. NY. McGraw- Hill.

Jackson, D., Hickman, L.D., Hutchinson, M., Andrew, S., \& Smith, J. (2014). Whistleblowing: An integrative literature review of data-based studies involving nurses. Contemporary Nurse, 48(2), 240-252. DOI: 10.1080/10376178.2014.11081946

Jackson, T.A., Meyer, J.P., \& Wang, X. (2013). Leadership, commitment, and culture: A meta-analysis. Journal of Leadership \& Organizational Studies, 20(1), 84-106. DOI: $10.1177 / 1548051812466919$

Kim, H., \& Kim, T. (2017). Emotional intelligence and transformational leadership: A review of empirical studies. Human Resource Development Review, 16(4), 377-393. DOI: $10.1177 / 1534484317729262$

Kim, M., Beehr, T.A., \& Prewett, M.S. (2018). Employee responses to empowering leadership: A metaanalysis. Journal of Leadership \& Organizational Studies, 25(3), 257-276. DOI: $10.1177 / 1548051817750538$

Kim, W., Khan, G.F., Wood, J., \& Mahmood, M.T. (2016). Employee engagement for sustainable organizations: Keyword analysis using social network analysis and burst detection approach. Sustainability, 8(7), 631. DOI: 10.3390/su807063.1

Kramer, M., Page, L., \& Klemic, G. (2018). Evolving leadership: New clues and cues toward environment and context. Journal of Leadership Studies, 12(4), 82-85. DOI: 10.1002/j1s.21618

Kuoppala, J., Lamminpää, A., Liira, J., \& Vainio, H. (2008). Leadership, job well-being, and health effects: A systematic review and a meta-analysis. Journal of Occupational and Environmental Medicine, 50(8), 904-915. DOI: 10.1097/JOM.0b013e31817e918d

Lacerenza, C. N., Reyes, D. L., Marlow, S. L., Joseph, D. L., \& Salas, E. (2017). Leadership training design, delivery, and implementation: A meta-analysis. Journal of Applied Psychology, 102(12). 1686-1718. DOI: 10.1037/ap10000241

Laloux, F. (2014). Reinventing organizations: A guide to creating organizations inspired by the next stage of human consciousness. Millis, MA: Parker-Nelson Publishing.

Leong, L. C., \& Fischer, R. (2011). Is transformational leadership universal? A meta-analytic investigation of multifactor leadership questionnaire means across cultures. Journal of Leadership \& Organizational Studies, 18(2), 164-174. DOI: 10.1177/1548051810385003 
Ligon, G. S., Wallace, J.H., \& Osburn, H. K. (2011). Experiential development and mentoring processes for leaders for innovation. Advances in Developing Human Resources, 13(3), 297-317. DOI: $10.1177 / 1523422311424708$

Lindberg, C., Nash, S., \& Lindberg, C. (2008). On the edge: Nursing in the age of complexity. Bordentown, NJ: Plexus Press.

Manderscheid, S., \& Ardichvili, A. (2008). A conceptual model for leadership transition. Performance Improvement Quarterly, 20(3-4), 113-129. DOI: 10.1002/piq.20006

Mannix, J., Wilkes, L., \& Daly, J. (2013). Attributes of clinical leadership in contemporary nursing: An integrative review. Contemporary Nurse, 45(1), 10-21. DOI: 10.5172/conu.2013.45.1.10

Martinez, A. J. S. (2016). Managing workplace violence with evidence-based interventions. Journal of Psychosocial Nursing, 54(9), 31-36. DOI: 10.3928/02793695-20160817-05

Mehdiabadi, A. H., \& Li, J. (2016). Understanding talent development and implications for human resource development: An integrative literature review. Human Resource Development Review, 15(3), 263-294. DOI: 10.1177/1534484316655667

Montano, D., Reeske, A., Franke, F. A., \& Huffmeier, J. (2017). Leadership, followers' mental health and job performance in organizations: A comprehensive meta-analysis from an occupational health perspective. Journal of Organizational Behavior, 38(3), 327-350. DOI: 10.1002/job.2124

Morgeson, F.P., DeRue, D. S, \& Karam, E.P. (2010). Leadership in teams: A functional approach to understanding leadership structures and processes. Journal of Management, 36(1), 5-39. DOI: $10.1177 / 0149206309347376$

Moura, A.A., Bernardes, A., Balsanelli, A.P., Zanetti, A.C., \& Gabriel, C.S. (2017). Leadership and nursing work satisfaction: An integrative review. Acta Paulista de Enfermagem, 30(4), 442-450. DOI: $10.1590 / 1982-0194201700055$

Nahavandi, A. (2015). The art and science of leadership.7th edition. Essex, England: Pearson Education Limited.

Nielsen, K., Randall, R., \& Christensen, K.B. (2010). Does training managers enhance the effects of implementing team-working? A longitudinal, mixed methods field study. Human Relations, 63(11), 1719-1741. DOI: 10.1177/0018726710365004

Nienaber, A. M., Romeike, P. D., Searle, R., \& Schewe, G. (2015). A qualitative meta-analysis of trust in supervisor-subordinate relationships. Journal of Managerial Psychology, 30(5), 507-534. DOI: 10.1108/JMP-06-2013-0187

Paglis, L. L. (2010). Leadership self-efficacy: Research findings and practical applications. Journal of Management Development, 29(9), 771-782. DOI: 10.1108/02621711011072487

Patton, M. Q. (2011). Developmental evaluation: Applying complexity concepts to enhance innovation and use. New York, NY: The Guilford Press.

Pratoom, K. (2018). Differential relationship of person-and task-focused leadership to team effectiveness: A meta-analysis of moderators. Human Resources Development Review, 17(4), 393-439. DOI: $10.1177 / 1534484318790167$

Robinson, V.M.J., Lloyd, C.A., \& Rowe, K.J. (2008). The impact of leadership on student outcomes: An analysis of the differential effects of leadership types. Educational Administration Quarterly, 44(5), 635-674. DOI: 10.1177/001316X08321509

Rockstuhl, T., Dulebohn, J.H., Ang, S., \& Shore, L.M. (2012). Leader-member exchange (LMX) and culture: A meta-analysis of correlates of LMX across 23 countries. Journal of Applied Psychology, 97(6), 1097-1130. DOI: 10.1037/a0029978

Rose, K. (2016). Examining organizational citizenship behavior in the context of human resource development: An integrative review of the literature. Human Resource Development Review, 15(3), 295-316. DOI: 10.1177/1534484316655668

Rose, K., Shuck, B., Twyford, D., \& Bergman, M. (2015). Skunked: An integrative review exploring the consequences of the dysfunctional leader and implications for those employees who work for them. Human Resource Development Review, 14(1), 64-90. DOI: 10.1177/1534484314552437 
Shuck, B. (2011). Four emerging perspectives of employee engagement: An integrative literature review. Human Resource Development Review, 10(3), 304-328. DOI: 10.1177/1534484311410840

Stavros, J. M., \& Hinrichs, G. (2009). The thin book of SOAR: Building strengths-based strategy. Bend, OR: Thin Book Publishing.

Suchman, A. (2002). Linearity, complexity and well-being. Medical Encounter, 16(4), 17-19.

Suchman, A. L., Sluyter, D. J., \& Williamson, P. R. (Eds.). (2011). Leading change in healthcare: Transforming organizations using complexity, positive psychology, and relationship-centered care. New York, NY: Radcliffe Publishing.

Torraco, R. J. (2005). Writing integrative literature reviews: Guidelines and examples. Human Resources Development Review, 4(3), 356-367. DOI: 10.1177/1534484305278283

Truong, M., Paradies, Y., \& Priest, N. (2014). Interventions to improve cultural competency in healthcare: A systematic review of reviews. BMC Health Services, 14(1). DOI: 10.1186/14726963-14-99

Wang, D., Waldman, D. A., \& Zhang, Z. (2014). A meta-analysis of shared leadership and team effectiveness. Journal of Applied Psychology, 99(2), 181-198. DOI: 10.1037/a0034531

Whitney, D., \& Trosten-Bloom, A. (2010). The power of appreciative inquiry: A practical guide to positive change (2nd ed.). San Francisco, CA: Berrett-Koehler Publishers.

Wollard, K.K., \& Shuck, B. (2011). Antecedents to employee engagement: A structured review of the literature. Advances in Developing Human Resources, 13(4), 429-446. DOI: $10.1177 / 1523422311431220$

Wong, C., Stake-Doucet, N., Lombardo, C., Sanzone, L., \& Tsimicalis, A. (2016). An integrative review of peer mentorship programs for undergraduate nursing students. Journal of Nursing Education, 55(3). DOI: 10.3928/01484834-20160216-04

Wren, J. T. (1995). The leader's companion: Insights on leadership through the ages. New York, NY: The Free Press.

Yahaya, R., \& Ebrahim, F. (2015). Leadership styles and organizational commitment: Literature review. Journal f Management Development, 35(2), 190-216. DOI: 10.1108/JMD-01-2015-0004 